\title{
CELL WALL-GLYCOLIPIDS PROFILING OF OIL PALM ROOTS DURING Ganoderma boninense INFECTION USING GAS CHROMATOGRAPHY- MASS SPECTROMETRY
}

\author{
ALEXANDER, $\mathrm{A}^{1}$; ABDULLAH, $\mathrm{S}^{2}$; DAYOU, $\mathrm{J}^{3}$ and CHONG, K $\mathrm{P}^{4 *}$
}

\begin{abstract}
Better understanding of the cell wall (CW)-glycolipids changes associated with basal stem rot (BSR) disease is essential for identifying the pathogen-host interaction to improve management and diagnostic measures. The aim of this study was to investigate the $C W$ changes in the glycolipids profile of oil palm roots during G. boninense infection. We carried out lipidomic analysis of glycolipids fractionated from $\mathrm{CW}$-lipids of oil palm seedlings artificially infected (AI) with G. boninense. Oil palm roots were harvested at three (first interval) and six months (second interval) post-AI from infected and control (uninfected) seedlings and were subjected to gas chromatography-mass spectrometry (GC-MS) based global lipidomic analysis. Principal component analysis (PCA) and partial least square-discriminant analysis (PLS-DA) confirmed 11 impaired glycolipids (six in the first and five in the second interval) associated to cell-signalling and break down of energy. Pyruvate metabolism and glycolysis or gluconeogenesis are the most perturbed pathways during the pathogenesis as revealed by pathway impact analysis. The possible utilisation of the glycolipids as biomarkers for diagnostic of Ganoderma infection was authenticated using the receiver operating characteristic (ROC) curve analysis. The current research suggests five glycolipids [Phosphatidylcholine (PC)(6:0/0:0), PC(2:0/2:0), Phosphatidic Acid (PA)(18:4(6Z,(Z,12Z,15Z)/0:0), PA(14:0/ 0:0) and $\gamma$-linolenic acid] as the potential biomarkers which may be further investigated for the early detection of BSR.
\end{abstract}

Keywords: cell wall-glycolipids profile, Ganoderma boninense, GC-MS, oil palm root.

Received: 2 June 2020; Accepted: 3 December 2021; Published online: 15 February 2022.

Agrifert Malaysia Sdn. Bhd., Unit 11.01, Level 11, Mercu 2, No. 3, Jalan Bangsar, KL Eco City, 59200 Kuala Lumpur, Malaysia.

2 Institute for Tropical Biology and Conservation, Universiti Malaysia Sabah, Jalan UMS, 88400 Kota Kinabalu, Sabah, Malaysia.

3 Vibration and Sound Research Group (e-VIBS), Faculty of Science and Natural Resources, Universiti Malaysia Sabah, Jalan UMS, 88400 Kota Kinabalu, Sabah, Malaysia.

4 Biotechnology Programme,

Faculty of Science and Natural Resources, Universiti Malaysia Sabah,

Jalan UMS, 88400 Kota Kinabalu,

Sabah, Malaysia.

* Corresponding author e-mail: chongkp@ums.edu.my

\section{INTRODUCTION}

Worldwide oil palm production has seen a steady increase in the past years. Not only the production contribute to the majority of vegetable oils and fats, it also helps to alleviate poverty in developing countries especially in Indonesia and Malaysia. However, one of the major concerns of oil palm plantation in Southeast Asia is the basal stem rot (BSR) disease caused by Ganoderma boninense which could result in great loss (Tay and Chong, 2016). BSR is caused by white rot fungi, Ganoderma sp. The fungus grows within the palm, degrades the lignin and cellulose components of the oil palm (Mohd Aswad et al., 2011). 
Early detection and diagnosis of BSR disease is rather difficult with the current knowledge and technologies, due to late emergence of the BSR disease symptoms. The current detection technique was done by isolation of the fruiting bodies appearing on the oil palm trunks or primary roots near soil level followed by molecular identification of the isolated fungus (Madihah et al., 2018). However, it is time consuming and by the time the foliar symptoms are observed, most of the tissues will have been killed by the fungus (Ariffin et al., 2000). Nonetheless, the most common detection method in the field by planters is by observing the appearance of foliar symptoms or the presence of Ganoderma fruiting bodies. Other diagnostic tools for early detection of G. boninense include using Ganoderma Selective Medium (GSM) (Ariffin and Idris, 1992), some lab-based molecular and biochemical detection methods such as ergosterol analysis and immunoassay (Chong et al., 2017). Recently, many researchers attempted to develops field detection methods, which include tomography (Idris et al., 2009), Molecularly Imprinted Polymer (MIP) Sensors (Markon et al., 2008) and hyperspectral reflectral data (Lelong et al., 2010). Some emerging detection methods include the usage of infrared spectroscopy (Dayou et al., 2014), ultrasonic (Ishaq et al., 2014; Najmie et al., 2011) and acoustics computed assisted tomography (Michael et al., 2020). However, most of these detection methods are still at the experimental stage, and are not readily available to serve for the earlier detection purpose.

It is important to point out that early detection of BSR is crucial for better management of BSR in oil palm. An effective and robust approach is essential to achieve such objectives. The emerging lipidomics research could offer a great option in determining possible biomarkers and biochemical pathways for BSR early detection purpose. Meanwhile, plant and fungal non-cytoplasmic lipids compositions, such as those that reside in $\mathrm{CW}$ and cell membrane were continuously and dynamically change according to the biological, chemical and physical stresses. In oil palmGanoderma interaction, one of the promising examples is the utilisation of ergosterol. Ergosterol is the main component of the fungal membrane that is useful as biomaker for the quantification of fungal biomass (Chong et al., 2014; Toh Choon et al., 2012). The membrane lipid ergosterol is found almost exclusively in fungi and is frequently used by microbiologists as an indicator of living fungal biomass, based on the assumption that ergosterol is labile, therefore, rapidly degraded after the death of fungal hyphae (Mille-Lindblom et al., 2004). The main advantage with ergosterol compared to other biomarkers, such as chitin and ATP is its specific association with fungi. G. boninense biomass is reported to be directly correlated with ergosterol concentration; therefore, provides a reliable diagnostic method for the BSR detection (Alexander et al., 2017; Chong et al., 2012a; Mohd Aswad et al., 2011). However, in the early stage of infection, ergosterol is difficult to be quantified due to the very small amount of fungal biomass that is present inside oil palm with addition of its labile properties. It is believed that other lipid composition, such as glycolipids are more stable than sterols, and unique due to their role in cellcell signalling. If researchers are able to exploit the glycolipids information in plant $\mathrm{CW}$ and cell membrane especially during oil palm-Ganoderma interaction, they might be able to identify the presence of specific glycolipids compounds that are produced during early stage of infection. Therefore, the present work aimed to investigate further into glycolipids composition during oil palmGanoderma interaction. The emerging lipidomics field of research could offer a great option for determining possible biomarkers and biochemical pathways that can discriminate infected palms from those that are not infected, thus potentially providing important fundamental information for BSR early detection approach.

\section{MATERIALS AND METHODS}

\section{Plant Material}

Eight months-old oil palm commercial seedlings (Dura $\times$ Pisifera) were purchased from Sawit Kinabalu Sdn. Bhd., Beaufort, Sabah, Malaysia. The seedlings were grown in polybags (38 $\mathrm{cm} \times 45 \mathrm{~cm}$ ) with soil and sand mixture (2:1) and all seedlings were watered and fertilised using Granular NPK 15:15:6:4 following the standard agronomic practices.

\section{Artificial Inoculation of Oil Palm Seedling using Rubber Wood Block (RWB) Technique}

RWB were prepared from rubber wood. G. boninense UMSBRIa strain (Chong et al., 2013) was inoculated to the RWB as inoculum for the artificial inoculation. The method of Khairudin (1991) was adopted for preparing the RWB (size of $6 \times 6 \times 12 \mathrm{~cm}$ ) with Ganoderma inoculum. RWB were washed with clean water, kept in autoclavable polypropylene plastic bags and autoclaved for $2 \mathrm{hr}$ at $121^{\circ} \mathrm{C}$. Each of the plastic bags was added with $100 \mathrm{ml}$ of sterile molten malt extract agar (MEA), and left to solidify after some time. Mycelial plugs with the size of $6 \mathrm{~mm}$ were excised from the edge of 14 days old $G$. boninense culture and inoculated on the RWB. The G. boninense-inoculated RWB were 
tightly sealed and kept for eight weeks in the dark at a temperature of $25 \pm 2^{\circ} \mathrm{C}$ until fully colonised. Artificial inoculation was conducted by following Khairudin (1991). Oil palm seedlings were carefully removed from polybags and later kept seated on the G. boninense-inoculated RWB to ensure the roots were in direct contact with the inoculum. Twenty oil palm seedlings were inoculated with Ganoderma RWB while another 20 uninoculated served as healthy control. Extreme care was taken to minimise injury during inoculation and planting. All oil palm seedlings were placed and arranged in complete randomised blocks under shed house conditions with $70 \%$ of shade protection and regular watering.

\section{Assessment of Disease Infection and Development}

For the assessment of disease infection and development, method described by Japanis et al. (2021) was adopted with a slight modification. All the inoculated oil palm seedlings were destructively sampled to determine the colonisation and establishment of G. boninense at two intervals: first interval [three months after artificial inoculation (AI)] and second interval (six months after AI). Ten seedlings were destructively sampled for each of the sampling period. Root tissues from the seedlings were harvested and washed under tap water, soaked in 99\% ethanol for $30 \mathrm{~s}$ before being dried under ambient air stream. The infection of $G$. boninense was detected based on the isolation and Ganoderma growth on GSM (Ariffin and Idris, 1992) and the presence of ergosterol (Chong et al., 2012b). Disease incidence was calculated using the Equation (1) (Masood et al., 2010):

$$
\begin{gathered}
\text { Disease } \\
\text { Incidence (DI) }
\end{gathered}=\frac{\begin{array}{c}
\text { Number of infected } \\
\text { plants }
\end{array}}{\begin{array}{c}
\text { Total number of plants } \\
\text { assessed }
\end{array}} \times 100
$$

Disease symptoms such as presence of fungal mass or fruiting bodies, yellowing or browning of leaf were determined using disease severity index (DSI) formula. DSI adopted from Abdullah et al. (2003) was used to determine the severity of the disease with score of 0 to 4 scales (Table 1 ). The DSI was calculated using the Equation (2):

$$
\text { DSI }=\frac{\begin{array}{l}
\text { Number of seedlings in } \\
\text { the rating } \times \text { rating number }
\end{array}}{\begin{array}{l}
\text { Total number of seedlings } \\
\text { assessed } \times \text { highest rating }
\end{array}} \times 100
$$

To assess the internal symptoms of Ganoderma infection, the seedlings were cut longitudinally across the bole region. Bole damage was assessed based on the scale as described by Nursabrina et al. (2012) (Table 2).

The bole damage index was calculated based on the internal symptoms of the bole tissues using the Equation (3):

$$
\begin{gathered}
\text { Bole damage } \\
\text { index }
\end{gathered}=\frac{\begin{array}{c}
\text { Number of seedlings in } \\
\text { the rating } \times \text { rating number }
\end{array}}{\begin{array}{l}
\text { Total number of seedlings } \\
\text { assessed } \times \text { highest rating }
\end{array}} \times 100
$$

\begin{tabular}{|c|c|}
\hline Disease class & Signs and symptoms \\
\hline 0 & $\begin{array}{l}\text { Healthy plants with green leaves without } \\
\text { appearance of fungal mycelium on any part } \\
\text { of plants }\end{array}$ \\
\hline 1 & $\begin{array}{l}\text { Appearance of white fungal mass on any part } \\
\text { of plants, with or without chlorotic leaves }\end{array}$ \\
\hline 2 & $\begin{array}{c}\text { Appearance of basidioma on any part of plants } \\
\text { with chlorotic leaves ( } 1 \text { to } 3 \text { leaves) }\end{array}$ \\
\hline 3 & $\begin{array}{c}\text { Formation of basidioma of any part of plants } \\
\text { with chlorotic leaves ( }>3 \text { leaves) }\end{array}$ \\
\hline 4 & $\begin{array}{c}\text { Formation of a well-developed basidioma and } \\
\text { the plants dried }\end{array}$ \\
\hline
\end{tabular}

TABLE 1. THE SIGNS AND SYMPTOMS OF DISEASE SEVERITY INDEX SCORED BASED ON DISEASE SCALE 0-4

Source: Abdullah et al. (2003).

TABLE 2. SIGNS AND SYMPTOMS OF BOLE INDEX SCORED BASED ON 0-4

\begin{tabular}{cl}
\hline Disease class & \multicolumn{1}{c}{ Signs and symptoms } \\
\hline 0 & Healthy \\
1 & up to $20 \%$ rotting of bole tissues \\
2 & $21 \%$ to $50 \%$ rotting of bole tissues \\
3 & $51 \%$ to $90 \%$ rotting of bole tissues \\
4 & over $90 \%$ rotting of bole tissues \\
\hline
\end{tabular}

Source: Nursabrina et al. (2012).

\section{Extraction of Cell Wall (CW)-Lipids}

Oil palm root materials (100 $\mathrm{g}$ of fresh weight) were lyophilised for $48 \mathrm{hr}$. Then the lyophilised materials were homogenised using a commercial blender until fine, followed by CW isolation as described by Canut et al. (2016) with a slight modification. CW materials were subjected to lipids extraction. Samples of G. boninense, healthy and infected CW (1 g) were added to $50 \mathrm{~mL}$ centrifuge tubes together with $10 \mathrm{~mL}$ of chloroform and methanol mixture with a volume ratio of $2: 1$. The tubes were agitated in temperature-controlled incubator shaker (Thermo Scientific Orbital and 
Incubator Shaker) for $120 \mathrm{~min}$ at $30^{\circ} \mathrm{C}$. The liquid phase was recovered with centrifugation of $1000 \mathrm{~g}$ for $10 \mathrm{~min}$. A 0.2 volume of miliQ ${ }^{\circledR}$ water was used to wash the solvent mixtures with additional agitation for another few seconds. The two phases were further separated by centrifugation at $1000 \mathrm{~g}$. The lower chloroform phase which contained the lipids was kept for further use while the aqueous upper phase was removed. A stream of $\mathrm{N}_{2}$ at temperature of $25 \pm 2{ }^{\circ} \mathrm{C}$ was used to dry the extracts.

\section{Fractionation of CW-Lipids Using Solid Phase Extraction (SPE)}

Fractionation of CW lipids extracts were performed using a Strata SI-1 silica disposable cartridge column (500 mg/6 mL) (Phenomenex) as described by Stobiecki et al. (1997) with slight modifications. The cartridge column was equilibrated by rinsing twice with $2 \mathrm{~mL}$ of chloroform using SPE manifold. Crude CW lipids dissolved in $2 \mathrm{~mL}$ of chloroform were loaded onto the column and the solvent was pulled through. Thereafter, the column was eluted with $10 \mathrm{~mL}$ of chloroform to elute sterol and neutral lipids fractions. Then, $10 \mathrm{~mL}$ of acetone and methanol mixture (9:1) was applied to elute glycolipid fraction. Finally, free fatty acids and phospholipid were eluted using $10 \mathrm{~mL}$ of methanol. Each fraction collected was dried under stream of nitrogen $\left(\mathrm{N}_{2}\right)$ prior to high-performance thin layer chromatography (HPTLC) analysis.

\section{Permethylation of Glycolipids}

Glycolipids permethylation was performed as described by Longo et al. (2013). Under $\mathrm{N}_{2}$ stream, glycolipids were dried and stored overnight at $20^{\circ} \mathrm{C}$ with silica gel. The glycolipids were then suspended in $150 \mu \mathrm{L}$ of anhydrous dimethyl sulphoxide (DMSO), agitated with few milligrams of anhydrous sodium hydroxide $(\mathrm{NaOH})$ and $80 \mu \mathrm{L}$ of iodomethane before incubated and shaken for $1 \mathrm{hr}$ at a temperature of $25 \pm 2^{\circ} \mathrm{C}$. Dichloromethane $(2 \mathrm{~mL})$ and deionised water $(2 \mathrm{~mL})$ were added to the mixture, agitated and centrifuged for removal of the aqueous upper layer. Two mL of deionised water was used to wash the organic phase for three times before dried under $\mathrm{N}_{2}$ stream.

\section{Gas Chromatography-Mass Spectrometry (GC-MS) Analysis of Glycolipids}

The GC-MS analysis of glycolipids was performed using GC-MS (Agilent, 5975C) with J\&W GC column (30 m x $250 \mu \mathrm{m} \times 0.25 \mu \mathrm{m}$; Agilent) according to method described by Nyberg (1986) with some modifications. For GC-MS detection, an electron ionisation system with ionisation energy of $70 \mathrm{eV}$ was used. The injector temperature was maintained at $280^{\circ} \mathrm{C}$. The carrier gas (helium) was set at the flow rate of $1.0 \mathrm{~mL} / \mathrm{min}$ before the sample $(1.0 \mu \mathrm{L})$ was introduced using the splitless mode. Three different temperature gradients were used for glycolipid analysis, $90^{\circ} \mathrm{C}$ (initial); $200^{\circ} \mathrm{C}$ at $20^{\circ} \mathrm{C} / \mathrm{min}$ $(10 \mathrm{~min}) ; 230^{\circ} \mathrm{C}$ at $10^{\circ} \mathrm{C} / \mathrm{min}(10 \mathrm{~min})$ and $265^{\circ} \mathrm{C} /$ min (final $5 \mathrm{~min}$ ). Spectra which was generated at $50-650 \mathrm{~m} / \mathrm{z}$ range at 20 scans per second with the solvent delay of $5 \mathrm{~min}$ were collected.

\section{Multivariate Data Analysis}

All raw spectrometric data were processed using open-source software MZmine (version 2.2.3). Chromatogram builder, peak detection, spectrum deconvolution, isotope filtering and peak grouping were used for data processing. The detected peaks were subjected to compound identification by searching NIST MS Search 2.0, METLIN database (http://metlin.scripps. edu/), MassBank (http://www.massbank.jp/), LipidMaps (http://www.lipidmaps.org/) and KEGG database (http://www.genome.jp/kegg) using exact molecular weights or MS fragmentation pattern data. The data were further normalised using the total summed metabolites' intensities and transformed by taking the natural log of the intensities' values of the analysed metabolites to make each feature comparable in magnitude to each other. Unsupervised principal component analysis (PCA) was used to analyse the pattern depicting metabolite differences and general clustering. While significantly altered metabolites between groups were identified using supervised partial least squares discriminant analysis (PLSDA) generated. The values of $R^{2}$ and $Q^{2}$ parameters were used to verify the fitness and predictive ability of the model. VIP analysis with VIP-score $>1.5$ was used to determine specific metabolites backing most significantly to the differences recognised by PLS-DA. Significantly the different metabolites were then used to generate a correlation heatmap identifying metabolites that cluster according to sample groups (healthy or infected). Distance measure was generated by Pearson correlations and clustering using the Ward algorithm.

\section{Identification of Altered Metabolic Pathways}

To identify the most relevant metabolic pathways involved in G. boninense-oil palm interaction, metabolic pathway analysis and pathway topology analysis were performed using MetPA, a web-based metabolomics tool for pathway analysis and visualisation (http://metpa. metabolomics.ca/MetPA) according to method described by Chen et al. (2015). The functional pathway analysis of potential biomarkers was based 
on the database source of the Kyoto Encyclopedia of Genes and Genomes (KEGG) (http://www. genome.jp/kegg/). The pathway topology analysis performed was as described by Fan et al. (2018) where the impact-value threshold was set as 0.10 and calculated from the analysis. Therefore any values above the threshold were rejected as potentially significant pathways.

\section{Potential Biomarkers Identification}

Potential biomarkers identification using Receiver Operating Characteristic (ROC) curve analysis was adopted from Barros et al. (2018) with some adjustments, by focusing on biomarkers that significantly altered in their metabolite's pathway. ROC analysis of the ROC curve analysis was conducted using the online ROCCET (http: / / www. roccet.ca). The area under the ROC curve (AUC) was used to calculate the sensitivity and specificity trade-offs. Areas under the ROC curve (AUC) is the method of choice for evaluating the performance of potential biomarkers: the greater the AUC (>0.7), the better the prediction of the model. Potential biomarkers with high sensitivity when infected with Ganoderma and low sensitivity when disease is absent were selected.

\section{RESULTS AND DISCUSSION}

\section{Assessment of Infection}

In the present work, successful inoculation was achieved using RWB technique as similar symptoms were developed at lower stem and bole tissues of inoculated oil palm seedlings, besides the presence of small white button (Figure 1) as described by Alizadeh et al. (2011); Naher et al. (2011); Nur Ain Izzati and Abdullah (2008). All Ganoderma-inoculated seedlings showed symptoms of infection after three (first interval) and six months (second interval) post-AI. To further confirm the success of colonisation of the pathogen in roots, G. boninense was isolated from the infected oil palm seedling roots using GSM. Positive result on GSM was also correlated with the detection of ergosterol content extracted from roots of inoculated seedlings according to the method demonstrated by Chong et al. (2012a). Ergosterol is a sterol component largely restricted to fungi and is absent in other living biomass. No ergosterol was detected in the healthy seedlings. Symptoms of Ganoderma infection and signs of the presence of Ganoderma on inoculated seedlings of the eight months old OP seedlings were noticed as early as three months after inoculation. The uninoculated seedlings did not show any symptoms of BSR infection and remained healthy until the end of the experiment. At first interval, concentration of ergosterol was $39.17 \mu \mathrm{g} / \mathrm{g}, \mathrm{DI}=100 \%$ and DSI $=30 \%$, meanwhile at second interval, the concentration of ergosterol increased significantly to $186.74 \mu \mathrm{g} / \mathrm{g}$, $\mathrm{DI}=100 \%$ parallel to the increased of DSI $=77.5 \%$ (Table 3) [data and calculation for ergosterol were obtained according to Chong et al. (2012a)]. Although some of the infected palms showed symptoms of BSR, DSI percentage at first interval was only $30 \%$ as most of the infected seedlings had lower score.Thus, this stage was regarded as the early infection due to the non-synchronous nature of BSR development (Rees et al., 2009). At second interval, progression of DSI was also in accordance with bole damage index of $47.5 \%$ (Table 3). All symptoms appeared at second interval, thus, regarded as the 'late infection' stage of BSR disease.
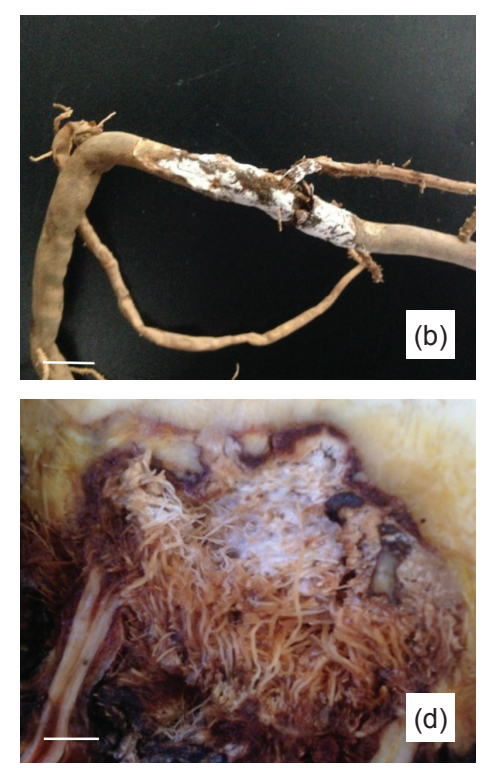

Figure 1. Physical evidence of successful artificial inoculation using Rubber Wood Block technique during first interval $(a-b)$ and second interval $(c-d)$. Bar=1 cm. 
TABLE 3. DISEASE ASSESSMENT OF TWO-TIME INTERVALS OF OIL PALM SEEDLINGS INOCULATED WITH Ganoderma

\begin{tabular}{lcc}
\hline Item & $\begin{array}{c}\text { First } \\
\text { interval }\end{array}$ & $\begin{array}{c}\text { Second } \\
\text { interval }\end{array}$ \\
\hline Disease incidence (DI) & $100 \%$ & $100 \%$ \\
Ergosterol $(\mu \mathrm{g} / \mathrm{g})$ & $39.17 \pm 0.75^{*}$ & $186.74 \pm 0.84^{*}$ \\
Disease severity index (DSI; $\%)$ & $30^{*}$ & $77.5^{*}$ \\
Bole damage index $(\%)$ & $0^{*}$ & $47.5^{*}$ \\
\hline
\end{tabular}

Note: *Significantly different at $p \leq 0.05$ by Tukey comparison test in their respective assessment. Values are the means of 10 replicates, where each replicate consists of a seedling.

\section{Differential Expression and Profile of Glycolipids Composition Related to Ganoderma Infection}

The differential metabolites between different sample groups were categorised according to the stage of infection assessed at two different intervals. Univariate statistical analysis performed on H-T1 (Healthy-First Interval) and IN-T1 (Infected-First Interval) datasets identified 31 glycolipids were significantly affected at first interval $\left(\log _{2}(\mathrm{FC})>2\right.$ and $p$-value $<0.05)$. Evaluation by PCA showed a clearly different distribution along PC1 covering $86.5 \%$ of the total variance (data not shown). In PLS-DA analysis, the components also showed the separation pattern similar to PCA analysis (Figure 2a). Using a VIP score of larger than 1.2 as a cutoff, six metabolites were found highly important to the separation (Figure 2). In IN-T1 dataset, pyruvic acid was down-regulated, while phosphatidic acid (PA) [18:4(6Z,9Z,12Z,15Z)/0:0], PA (14:0/0:0), phosphatidylcholine (PC) (2:0/2:0), PA (16:0/0:0) and $\gamma$-linoleic acid shows up-regulation trend in relation to H-T1. The glycolipids produced by various microorganisms contain different monoor disaccharides, conjugated with long-chain fatty acids or hydroxyl fatty acids through either acetyl or glycosidic linkages, and some of them exhibit antibiotic (Teichmann et al., 2011). The preferential loss of a fatty acid molecule from the glycerol backbone is most likely due to kinetic control of the gas-phase fragmentation process, thus, leading to the detection of fatty acids in the glycolipids analysis (Zianni et al., 2013).

At second interval, 48 metabolites were significantly regulated upon $G$. boninense infection. PCA model for the classification of the H-T2 (Healthy-Second Interval) and IN-T2 (InfectedSecond Interval) groups obtained satisfactory validation with $85.1 \%$ variance along PC1 (data not shown). The PLS-DA model was used to elucidate the most reliable class-discriminating metabolites that were highly diagnostic for group separation (Figure 2b). Together with the VIP scores $(>1.2)$ from the PLS-DA model, five metabolites with the highest values were identified, out of which, two metabolites (pyruvic acid and lignoceric acid) were down-regulated, while valeric acid, myriocin and $(4 \mathrm{E}, 6 \mathrm{E}, \mathrm{d} 14: 2)$ sphingosine were found up-regulated in IN-T2 groups (Figure 2b). Glycolipids profiling in the infected samples changed most significantly from their healthy controls at second interval, compared to first interval suggesting regulation of primary metabolism also occurs during plant-pathogen interactions. Using univariate analysis, IN-T1 vs. $\mathrm{H}-\mathrm{T} 1$ and IN-T2 vs. H-T2 shared one metabolite, pyruvic acid that was down-regulated in infected samples at both intervals. Evidence for the role of glycolipids in plant defense responses has been provided by experiments showing the induction of genes involved in carbohydrate metabolism upon challenge by pathogens or pathogen-derived elicitors (Rojas et al., 2014).

Apparently, fatty acid consisting of odd number of carbon atom chain, such as valeric acid might contribute to the regulation of systemic induced resistance (Kuć and Tuzun, 1990). Detection of myriocin, fungal secondary metabolites is one of most widely studied extraordinary sphingoid bases. Intriguingly, in spite of increased accumulation of myriocin, a long-chain sphingoid base, $(4 \mathrm{E}, 6 \mathrm{E}, \mathrm{d} 14: 2)$ sphingosine was also increased simultaneously. These long-chain bases are important intermediates and signalling molecules in the sphingolipid catabolic pathway (Speigel and Milstien, 2002). The levels of long-chain bases in healthy tissues are usually low, however the study found that the treatment of the corn tissue with mycotoxins can increase their level dramatically (Wright et al., 2003). Plant-pathogen interactions have implicated disruption of sphingolipid synthesis and buildup of long-chain bases during the hypersensitive response in programmed cell death associated with the plant defense response. The toxins myriocin resulting in an accumulation of sphingiocine associated with plant necrosis promotion (Tanaka et al., 1993) and programmed cell death (apoptosis) in plant tissues (Wang et al., 1996) is related to their detection in the second interval. The response to these toxins may be complex and apparently involves the participation of several signalling pathways (Asai et al., 2000), leading to long-chain base accumulation and cell death. But if long-chain base synthesis is concurrently inhibited, long-chain base build-up is prevented and the toxic effects are at least partly blocked (Spassieva et al., 2002). These findings propose that sphingoid long-chain bases may be significant in signalling or regulatory roles in plant defense, and higher levels in plant tissues lead to cell death.

Toidentify the changesin glycolipid composition between infected and healthy samples at first and second interval, the multivariate statistical analysis was performed. To answer a question which the first two t-tests was unable to address, an analysis of variance (ANOVA) test was conducted 
(a)

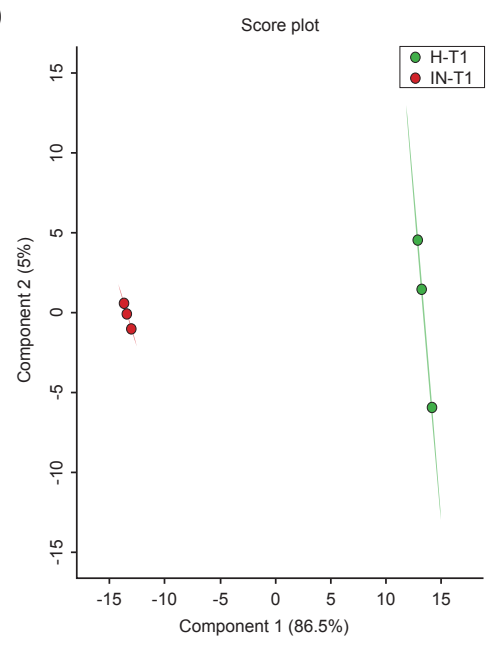

(c)

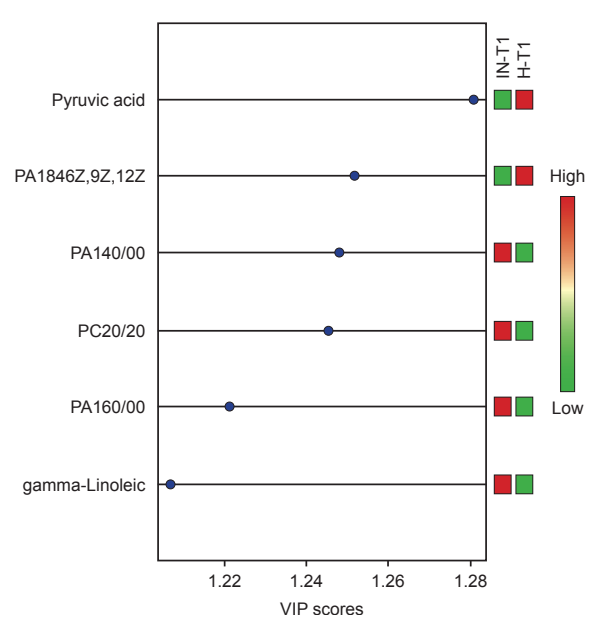

(b)

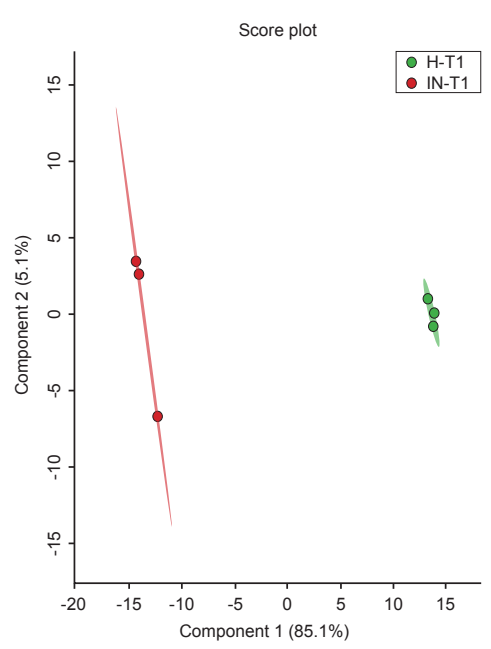

(d)

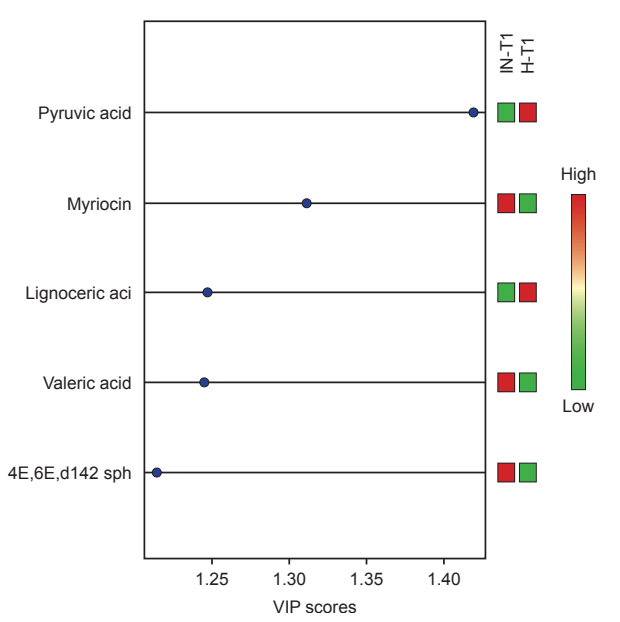

Note: H - Healthy seedlings; IN - Ganoderma-inoculated seedlings; T1 - First interval (three months postartificial inoculation (AI)); T2 - Second interval (six months post-AI).

Figure 2. Partial least square-discriminant analysis (PLS-DA) of (a) IN-T1 vs. H-T1 and (b) IN-T2 vs. H-T2; variable importance in projection (VIP) score plot selected from PLS-DA model with $p>0.05$ and (VIP) scores $>1.2$ of (c) IN-T1 vs. H-T1 and (d) IN-T2 vs. H-T2. Colour key indicates metabolite expression value, green: Lowest, red: highest. Analysis by Metaboanalyst consists $n=3$ replicates for each group.

to identify the common changes in glycolipids profiles. ANOVA test revealed a total of 31 significant features with $p$-value $<0.05$. PCA showed that $79.5 \%$ of the total variance in the data was represented by the first two principal components (Figure 3a). PCA scores plot show H-T1, H-T2 and IN-T1 were separated from IN-T2 along PC1, indicating that IN-T1 and IN-T2 profiles were very distinct to each other. To obtain a more reliable statistical analysis and the specific loadings, a PLS-DA model was used to discriminate healthy and infected groups. PLS-DA was able to discriminate lipid samples based on the treatment they received with a good cross-validated model performance using the first two latent variables $\left(\mathrm{R}^{2}=0.972 ; \mathrm{Q}^{2}=0.945\right)$. PLSDA additionally informed upon which metabolites were most important for the classification model via their VIP scores and identified nine metabolites (VIP values $>1.5$ ) (Figure 3b). Further analysis using heatmap recognised two metabolites (Pyruvic acid and lignoceric acid), from healthy (H-T1 and H-T2) groups showed highly significant of differences from infected groups, suggesting that these two metabolites might significantly perturbed during G. boninense infection (Figure 3c). Pyruvic acid, a product of glycolysis and a very-long-chain of fatty acids such as lignoceric acid exert crucial functions in plant developmental processes, thus, when their levels are perturbed, is marked phenotypic consequences in plant growth (De Bigault Du Granrut and Cacas, 2016). Meanwhile, ethyl heptanoate, PC (6:0/0:0), PC (2:0/2:0), $\gamma$-linoleic acid, methyl stearate, PA [18:4(6Z,9Z,12Z,15Z)/0:0] and PA (14:0/0:0) were significantly up-regulated in 
IN-T1 and IN-T2 samples. These metabolites could be used as potential biomarkers to discriminate infected and healthy oil palm seedlings. Production of biologically active lipids, such as PA and PC has been identified as a major source of lipid second messenger and play an important role in signal transduction. Increases in PA concentration have been observed under various environmental stresses and were detected during early response in the Cladosporium fulvum-4/Avirulence-4 interaction (de Jong et al., 2004). Induction of reactive oxygen species (ROS) formation is also linked to PA (Park et al., 2004). Signal-induced production of $\mathrm{PA}$ in the cell was accompanied by the increases of PC, in contrast with the other study by Xie et al. (2015). Accumulation of PC might derive from the pathogen's membrane cell (Siebers et al., 2016). Increased level of methyl stearate was also in parallel to the findings in vegetative tissues of sunflower mutants (Cantisán et al., 1999). This compound is converted into linoleic acid, a precursor for the defense signalling molecules jasmonic acid (Wang et al., 2017). Jasmonic acid functions as a trigger to the phenylpropanoid pathway to increase the synthesis of phenolic compounds (Gundlach et al., 1992). Significant increment of $\gamma$-linoleic acid was also consistently observed in Arabidopsis thaliana infected with Sclerotinia sclerotiorum at an all-time point $(3,6$ and $24 \mathrm{hr}$ after infection). Linoleic acid was also associated in pathogenesis and resistancerelated metabolites of wheat, upon infection with Fusarium head blight disease (Hamzehzarghani et al., 2008). No previous evidence on accumulation of ethyl heptanoate has been reported elsewhere. (a)

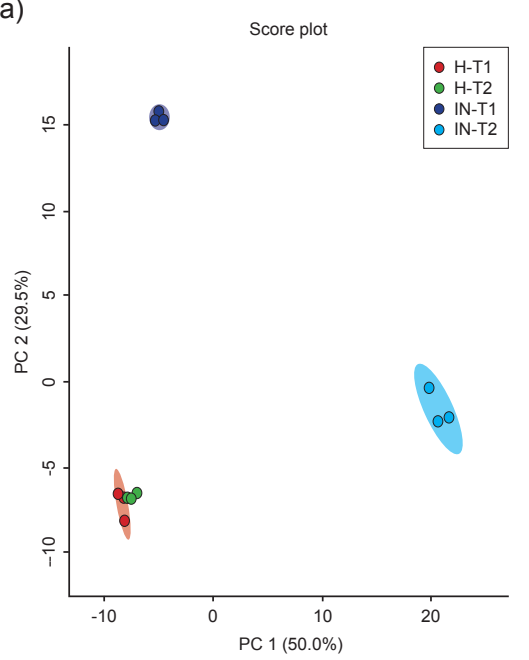

(b)

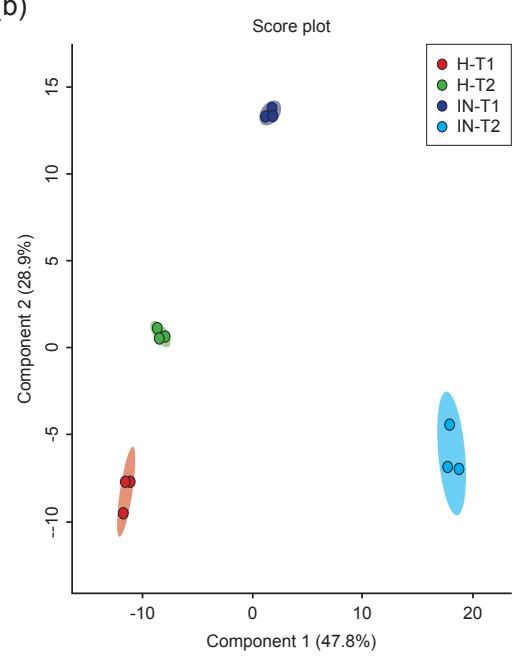

(c)

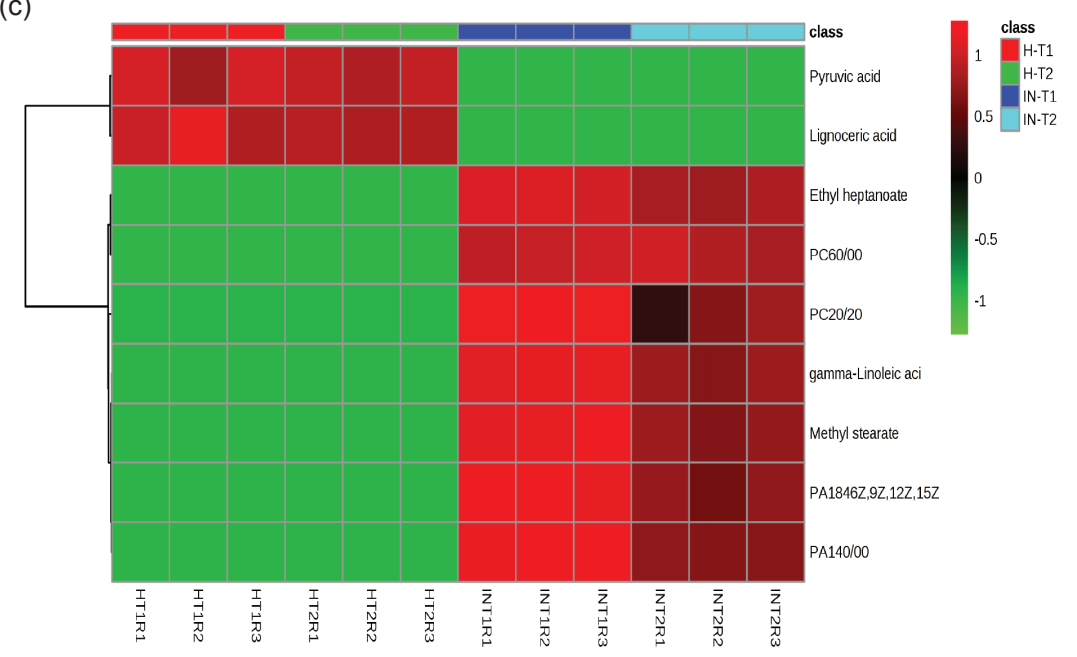

Note: H - Healthy seedlings; IN - Ganoderma-inoculated seedlings; T1 - First interval [three months post-artificial inoculation (AI)]; T2 - Second interval (six months post-AI).

Figure 3. Multivariate cluster analysis of glycolipids profiles of H-T1 vs. IN-T1 vs. H-T2 vs. IN-T2 at first and second intervals. (a) Score-plot of principal component analysis (PCA), (b) Score-plot of partial least square-discriminant analysis (PLS-DA), and (c) Heatmap visualisation analysis of metabolites (VIP score $>1.5 ; p>0.05$ ) identified from PLS-DA model with a potential identity to distinguish between infected and healthy groups. Colour key indicates metabolite expression value, green: Lowest, red: highest. Analysis by Metaboanalyst consists $n=3$ replicates for each group. 


\section{Metabolite Pathways Related to G. boninense Infection}

Metabolic pathway analysis was performed to reveal the most relevant pathways related to Ganoderma infection. The impact score (IS) of these pathways calculated from pathway topology analysis above 0.10 was screened out as potential target pathway. Significant features with $p$-value $<0.05$ and PLS-DA VIP score $>1.5$ from multivariate analyses were pooled and further subjected to pathway analysis. The result in Figure 4 shows that two pathways; pyruvate metabolism (IS: 0.1129) and glycolysis or gluconeogenesis (IS: 0.1091) were associated with G. boninense throughout the whole experiment. As a hemibiotrophic fungal pathogen, G. boninense first establishes a biotrophic interaction with the host plant and later switches to a destructive necrotrophic lifestyle. This study suggests that when the fungus breaches into the host $\mathrm{CW}$ to access nutrients that are available in the starch reservoir (biotroph stage) (Rees et al., 2009), it causes the host plant to induce the signaling pathway and its defensive environment. Fascinatingly however, G. boninense seems to be able to avoid direct contact with the defense compounds produced by the defensive signalling pathway, causing the infection to progress to the latent and the later stage of BSR disease as demonstrated in Glucosinolate metabolites for Arabidopsis thaliana defense mechanism against several pathogens (Clay et al., 2009). When G. boninense initiates the necrotrophic program, it causes interference with the carbohydrate metabolism pathways (Su et al., 2021). Ganoderma boninense invasion substantially alters the primary metabolism of oil palm roots seedlings as seen by the downregulation of pyruvic acid and carbohydrate metabolism at first and second intervals. Pyruvic acid declines early in the infection process and continues to decline during the biotrophic stage. In this study, it was suggested that G. boninense avoided effective defenses by hijacking pyruvic acid-associated pathways as shown in Figure 4. During G. boninense colonisation, OP seedling induced the downregulation of pyruvic acid; involving itself in carbohydrate catabolism processes such as glycolysis or gluconeogenesis and pyruvate metabolism. It has been suggested that the energy saved by down-regulation of primary metabolism is diverted and used for defense responses (Rojas et al., 2014). As plant defense responses require an abundant supply of energy, primarily derived from primary metabolic processes (Bolton, 2009). However, the ability of G. boninense to utilise the plant-carbohydrate upon colonisation decreases this metabolite, thus, weakening the oil palm into 'starvation', consequently exposing it to G. boninense colonisation (Divon and Fluhr, 2007; Li et al., 2019).

\section{Identification of Biomarkers Associated with G. boninense Infection}

Biomarkers were identified using a subset of metabolites from the multivariate statistical analyses outlined earlier, as these metabolites were capable of discriminating between sample groups. ROC analysis was performed to further characterise the predictive value of selected metabolites independently. Disease analysis employs the ROC

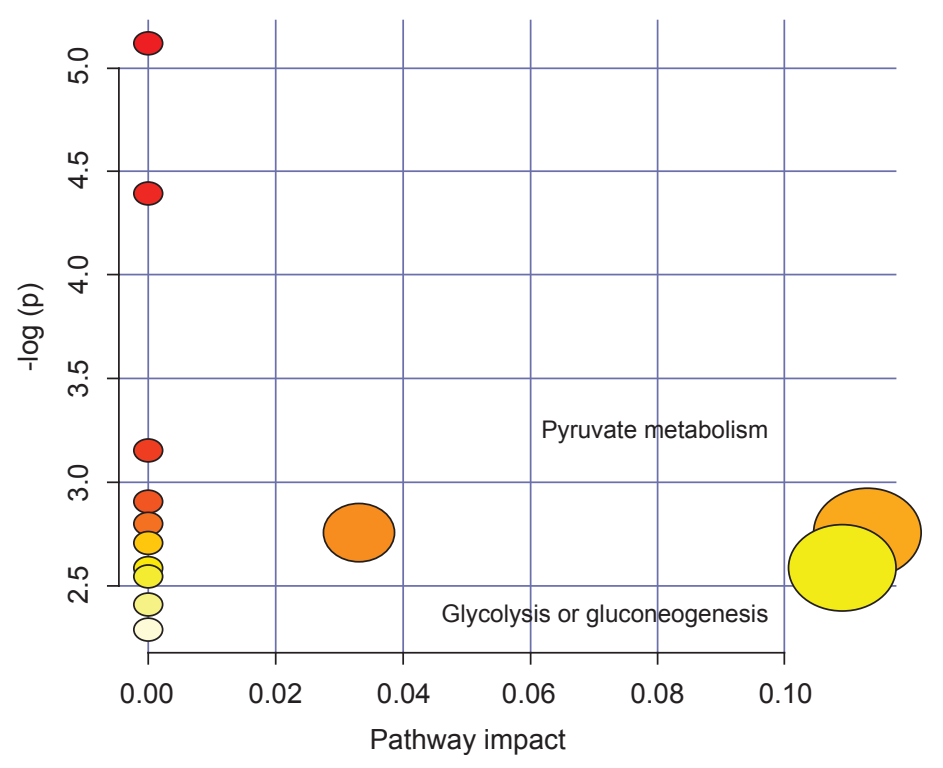

Figure 4. The pathway impact analysis of cell-wall lipid metabolites selected from multivariate analysis (from whole experiment) using MetPA. Each circle represents a matched pathway. Metabolic pathways with impact values $>0.05$ were considered to be perturbed. 
curve and the area under the ROC curve (AUC) to obtain a numerical value of the relationship between the specificity and sensitivity of a biomarker. The sensitivity and specificity indicate the probability tests for correctly identifying infected palms with the disease and without the disease, respectively (Lalkhen and McCluskey, 2008). AUC value of 1.0 shows a perfect prediction in term of the sensitivity and specificity of the diagnostic test (Greiner et al., 2000), thus, these metabolites could be used as biomarkers to differentiate the infected and healthy tissues. To confirm the prediction of Ganodermainfected tissue, a combination of more than one discriminatory metabolite was developed via a

(a)

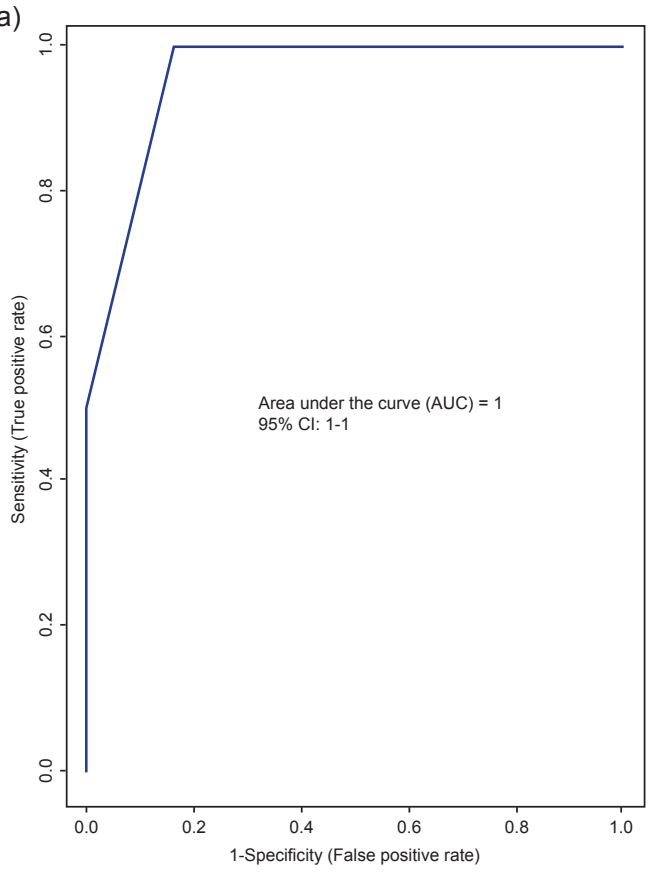

logistic regression analysis and showed that the combination of metabolite also resulted in a better discriminator with AUC equal to 1 (Figure $5 a$ ), and a clear separation and discrimination were observed between the infected and healthy samples in the probability view (Figure 5b). The average accuracy based on 100 cross validations (CV) was 1 in this study (Figure 5c). Having an average accuracy close to 1 indicates a more valid CV prediction. Box-whisker plots revealed that all five biomarkers exhibited significantly higher levels in infected samples than in healthy $(p<0.05)$ (Figure 6$)$. Since the five biomarkers showed the AUC value of 1.0, they were selected as biomarkers of infected palms. (b)

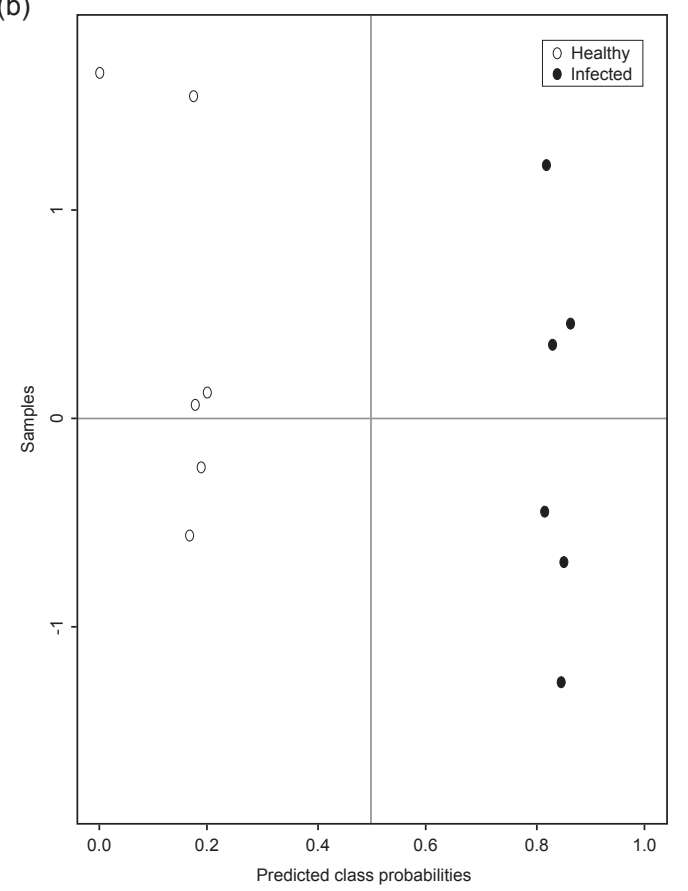

(c)

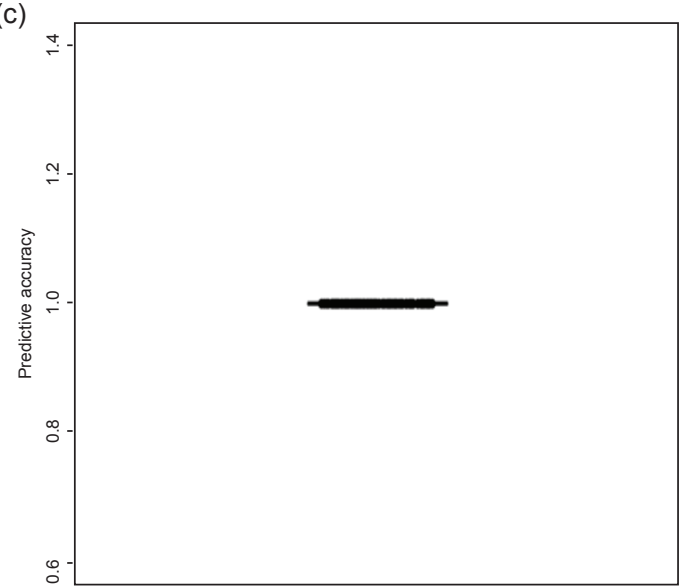

Figure 5. Biomarker analysis results (ROC view). Statistical method to evaluate infected and healthy discrimination using selected potential metabolites. (a) Probability view, (b) cross validation prediction, and (c) accuracy of selected metabolites, $P C(6: 0 / 0: 0), P C(2: 0 / 2: 0), P A(18: 4(6 Z, 9 Z, 12 Z, 15 Z) / 0: 0)$, PA(14:0/0:0) and $\gamma$-linolenic acid. 
(a)

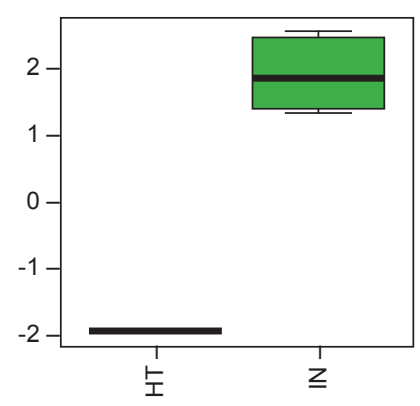

(c) $\mathrm{PA}[18: 4(6 Z, 9 Z, 12 Z, 15 Z) / 0: 0]$

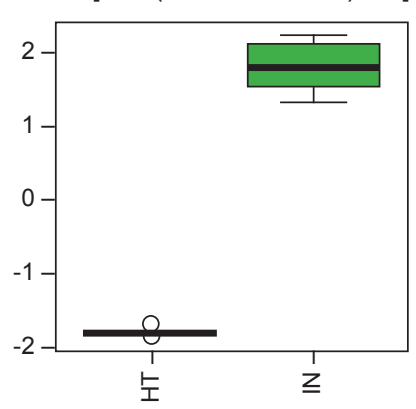

(b)

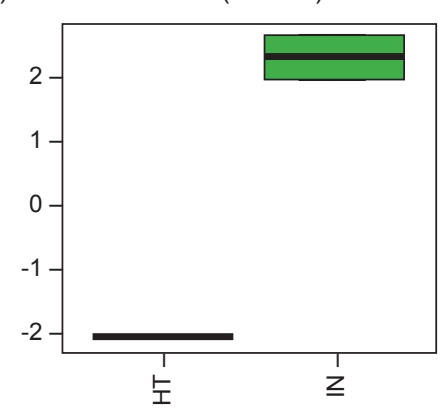

(d)

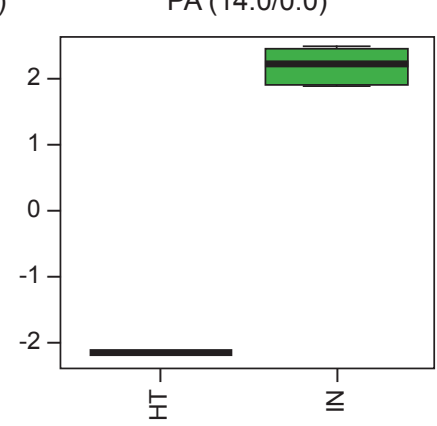

(e)

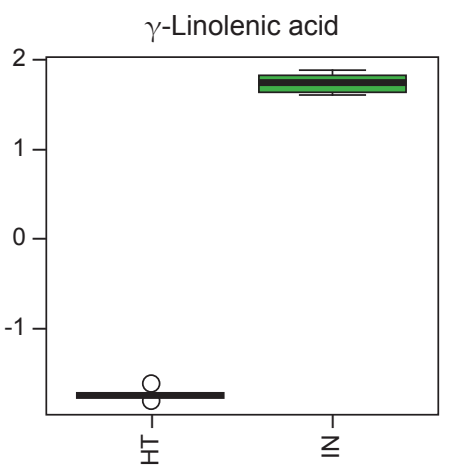

Figure 6. Box-and-whiskers plots representing relative abundance of (a) PC(6:0/0:0); (b) PC(2:0/2:0); (c) PA(18:4(6Z,9Z,12Z,15Z)/0:0); (d) PA(14:0/0:0); (e) $\gamma$-linolenic acid in Ganoderma-infected and healthy oil palm seedlings. The relative abundance of each metabolite in lipid profiles of Ganoderma-infected was significantly higher than healthy groups using Student's t-test ( $p$-value $<0.05$ ).

\section{CONCLUSION}

The current study indicates that lipid-profiling techniques combined with the chemometric analysis can develop a detailed picture and provide a broader assessment of the glycolipid change that occurs in oil palm roots $\mathrm{CW}$ in response to the BSR disease. The study provides an insight into the complex hostpathogen interactions, and also discovers altered lipidomics/metabolomics pathways involved in disease pathogenesis. Pyruvate metabolism and glycolysis or gluconeogenesis are the most perturbed pathways during the pathogenesis. Simulation of defense pathway using synthesised metabolites in oil palm may probably lead to the enhancement of defense reactions, leading to the formation of physiochemical reactions barrier which prevents the invasion of $G$. boninense. The five metabolites: PC(6:0/0:0), PC(2:0/2:0), PA[18:4(6Z,(Z,12Z,15Z)/ 0:0],
PA(14:0/ 0:0) and $\gamma$-linolenic acid which had been identified and analysed in the present work and could be used as diagnostic biomarkers to identify G. boninense infection for an earlier control. Future research using genetic approach on these biomarkers will deepen the understanding of their importance in defense/cell signaling and the role of glycolipid in plant-pathogen interaction in facilitating the development of the BSR early detection approach.

\section{ACKNOWLEDGEMENT}

The authors wish to thank the Ministry of Higher Education of Malaysia for funding the project through the Fundamental Research Grant Scheme (FRG0342-ST-2/2013). Support and service provided by the Universiti Malaysia Sabah are also gratefully acknowledged. 


\section{REFERENCES}

Abdulllah, F; Ilias, G N M; Nelson, M; Nur Ain Izzati, M Z and Umi Kalsom, Y (2003). Disease assessment and the efficacy of Trichoderma as a biocontrol agent of basal stem rot of oil palm. Res. Bull. Sci. Putra, 11: 31-33.

Alexander, A; Abdullah, S; Rosall, S and Chong, K P (2017). Evaluation of the efficacy and mode of action of biological control for suppression of Ganoderma boninense in oil palm. Pak. J. Bot., 49(3): 1193-1199.

Alizadeh, F; Abdullah, S N A; Khodavandi, A; Abdullah, F; Yusuf, U K and Chong, P P (2011). Differential expression of oil palm pathology genes during interactions with Ganoderma boninense and Trichoderma harzianum. J. Plant Physiol., 168: 11061113.

Ariffin, D and Idris, A S (1992). The Ganoderma selective medium (GSM). PORIM Information Series No. 8.

Ariffin, D; Idris, A S and Singh, G (2000). Status of Ganoderma in oil palm. Ganoderma Diseases of Perennial Crops (Flood, J; Bridge, P D and Holderness, M eds.). CABI Publishing, Wallingford. p. 49-68.

Asai, T; Stone, J M; Heard, J E; Kovtun, Y; Yorgrey, P; Sheen, J and Ausubel, F M (2000). Fumonisin B1induced cell death in Arabidopsis protoplasts requires jasmonate-, ethylene-, and salicylate-dependent signaling pathways. Plant Cell, 12: 1823-1835.

Barros, R P C; da Cunha, E V I; Catão, R M R; Scotti, L; Souza, M S R; Brás, A A Q and Scotti, M T (2018). Virtual screening of secondary metabolites of the genus Solanum with potential antimicrobial activity. Rev. Bras. Farmacogn., 28: 686-691.

Bolton, M D (2009). Primary metabolism and plant defense - Fuel for the fire. Mol. Plant Microbe Interact., 22: 487-497.

Cantisán, S; Martínez-Force, E; Álvarez-Ortega, R and Garcés, R (1999). Lipid characterization in vegetative tissues of high saturated fatty acid sunflower mutants. J. Agric. Food Chem., 47(1): 78-82.

Canut, H; Albenne, C and Jamet, E (2016). Isolation of the cell wall. Isolation of Plant Organelles and Structures. Methods in Molecular Biology. (Taylor, N and Millar, A eds.). Vol. 1511: Humana Press, New York, USA. p. 171-185.

Chen, H-H; Tseng, Y J; Wang, S-Y; Tsai, Y-S; Chang, C-S; Kuo, T-C; Yao, W-J; Shieh, C-C; Wu, C-H and Kuo, P-H (2015). The metabolome profiling and pathway analysis in metabolic healthy and abnormal obesity. Int. J. Obes., 39(8): 1241-1248.

Chong, K P; Atong, M and Rossall, S (2012a). The role of syringic acid in the interaction between oil palm and Ganoderma boninense, the causal agent of Basal Stem Rot. Plant Pat., 61: 953-963. DOI: $10.1111 /$ j.1365-3059.2011.02577x.

Chong, K P; Atong, M and Rossall, S (2012b). The roles of syringic, caffeic and 4-hydroxybenoic acid in Ganoderma-oil palm interaction. Asian J. Microbiol. Biotechnol. Environ. Sci., 14(2): 157-166.

Chong, K P; Abdullah, S and Ng, T L (2013). Molecular fingerprint of Ganoderma spp. from Sabah, Malaysia. Int. J. Agric. Biol., 15: 1112-1118.

Chong, K P; Dayou, J and Alexander, A (2017). Detection and Control of Ganoderma Boninense in Oil Palm Crop. Springer Briefs in Agriculture. Springer, Cham. 77 pp.

Chong, K P; Eldaa, P A and Dayou, J (2014). Relation of Ganoderma ergosterol content to basal stem rot disease severity index. Adv. Environ. Biol., 8(14 (Special)): 14-19.

Clay, N K; Adio, A M; Denoux, C; Jander, G and Ausubel, F M (2009). Glucosinolate metabolites required for an Arabidopsis innate immune response. Science, 323(5910): 95-101.

Dayou, J; Alexander, A; Sipaut, C S; Chong, K P and Lee, P C (2014). On the possibility of using FTIR for detection of Ganoderma boninense in infected oil palm tree. Int. J. Adv. Agric. Environ. Eng., 1(1): 161-163.

De Bigault Du Granrut, A and Cacas, J L (2016). How very-long-chain fatty acids could signal stressful conditions in plants? Front. Plant Sci., 7: 1490.

de Jong, C F; Laxalt, A M; Bargmann, B O; de Wit, P J; Joosten, M H and Munnik, T (2004). Phosphatidic acid accumulation is an early response in the Cf-4/ Avr4 interaction. Plant J., 39: 1-12.

Divon, HH and Fluhr, R (2007). Nutrition acquisition strategies during fungal infection in plants. FEMS Microbiol. Lett., 266 (1): 65-74.

Fan, W; Ge, G; Liu, Y; Wang, W; Liu, L and Jia, Y (2018). Proteomics integrated with metabolomics: Analysis of the internal causes of nutrient changes in alfalfa at different growth stages. BMC Plant Biol., 18(1): 1-15.

Greiner, M; Pfeiffer, D and Smith, R D (2000). Principles and practical application of the receiver- 
operating characteristic analysis for diagnostic tests. Prev. Vet. Med., 45: 23-41.

Gundlach, H; Müller, M J; Kutchan, T M and Zenk, M H (1992). Jasmonic acid is a signal transducer in elicitor-induced plant cell cultures. Proc. Natl. Acad. Sci. USA, 89: 2389-2393.

Hamzehzarghani, H; Paranidharan, V; Abu-Nada, Y; Kushalappa, A C; Mamer, O and Somers, D (2008). Metabolic profiling to discriminate wheat near isogenic lines, with quantitative trait loci at chromosome 2DL, varying in resistance against Fusarium head blight. Can. J. Plant Sci., 88: 789-797.

Idris, A S; Mazliham, M S and Madihah, A Z (2009). Current technologies for detection of Ganoderma in oil palm. Proc. Agric. Biotechnol. Sustain. Conf.PIPOC. MPOB, Bangi. p. 81-98.

Ishaq, I; Alias, M S; Kadir, J and Kawawani, I (2014). Detection of basal stem rot disease at oil palm plantations using sonic tomography. J. Sustain. Sci. Manag., 9(2): 52-57.

Japanis, F G; Chan, Y S and Chong, K P (2021). Evaluation on the effectiveness of combination of biocontrol agents in managing Ganoderma boninense of oil palm. Malays. J. Microbiol., 17(1): 1-10.

Khairudin, H (1991). Pathogenicity of three Ganoderma species on oil palm seedlings. J. Perak Planters Assoc. p. 43-49.

Kuć, J and Tuzun, S (1990). Metabolic regulation of resistance genes in tobacco for the control of blue mold. Blue Mold Disease of Tobacco Literature Service (Main, C and Spurr, H eds.). North Carolina State University, Raleigh. p. 35-46.

Lalkhen, A G and McCluskey, A (2008). Clinical tests: Sensitivity and specificity. Cont. Edu. Anaesth, Critical Care Pain, 8: 221-223.

Lelong, C C; Roger, J-M; Brégand, S; Dubertret, F; Lanore, M; Sitorus, N; Raharjo, D and Caliman, J-P (2010). Evaluation of oil-palm fungal disease infestation with canopy hyperspectral reflectance data. Sensors (Basel), 10(1): 734-747.

Li, P; Liu, W; Zhang, Y; Xing, J; Li, J; Feng, J; Su, X and Zhao, J (2019). Fungal canker pathogens trigger carbon starvation by inhibiting metabolism in poplar stems. Sci. Rep., 9: 10111.

Longo, L V G; Nakayasu, E S; Lopes, F G; Vallejo, M C; Matsuo, A L; Almeida, I C and Puccia, R (2013). Characterization of cell wall lipids from the pathogenic phase of Paracoccidioides brasiliensis cultivated in the presence or absence of human plasma. PLoS ONE, 8(5): e63372.

Madihah, A Z; Maizatul-Suriza, M; Idris, A S; Bakar, M F A; Kamaruddin, S; Bharudin, I; Abu Bakar, F D and Murad, A M A (2018). Comparison of DNA extraction and detection of Ganoderma, causal of basal stem rot disease in oil palm using loopmediated isothermal amplification. Malays. Appl. Biol. J., 47(5): 119-127.

Markon, M A; Shakaff, A Y; Adom, A H; Ahmad, $\mathrm{M} \mathrm{N}$ and Abdullah, A H (2008). The feasibility study of utilising electronic nose and ANN for plant malaise detection. Proc. MUCET Malaysian Universities Conf. Eng. Technol. (MUCET). Putra Brasmana, Perlis, Malaysia. p. 1-6.

Masood, A; Saeed, S; Iqbal, N; Malik, M T and Kazmi, M R (2010). Methodology for the evaluation of symptoms severity of mango sudden death syndrome in Pakistan. Pak. J. Bot., 42(2): 1289-1299.

Michael, M L; Chong, K P; Zenian, S; Lo, A S V and Dayou, J (2020). On the propagation of Ganoderma boninense infection of basal stem rot in oil palm with the aid of acoustics computed assisted tomography. Tran. Sci. Tech., 7(3-2): 165-171.

Mille-Lindblom, C; von Wachenfeldt, E and Tranvik, L J (2004). Ergosterol as a measure of living biomass: Persistance in environmental samples after fungal death. J. Microbiol. Methods, 59: 253-262.

Mohd As'wad, A W; Sariah, M; Paterson, R R M; Zainal Abidin, M A and Lima, N (2011). Ergosterol analyses of oil palm seedlings and plants infected with Ganoderma. Crop Prot., 30: 1438-1442.

Naher, L; Ho, C-L; Tan, S G; Yusuf, U K and Abdullah, F (2011). Cloning of transcripts encoding chitinases from Elaeis guineensis Jacq. and their expression profiles in response to fungal infections. Physiol. Mol. Plant Pathol., 76: 96-103.

Najmie, M M K; Khalid, K; Sidek, A A and Jusoh, M A (2011). Density and ultrasonic characterization of oil palm trunk infected by Ganoderma boninense disease. Meas. Sci. Rev., 11(5): 160-164.

Nur Ain Izzati, M Z and Abdullah, F (2008). Disease suppression in Ganoderma-infected oil palm seedlings treated with Trichoderma harzianum. Plant Protect. Sci., 44: 101-107.

Nursabrina, A A; Sariah, M and Zaharah, AR (2012). Suppression of basal stem rot disease progress on oil palm (Elaeis guineensis) after copper and calcium 
supplementation. Pertanika J. Trop. Agric. Sci., 35: 13-24.

Nyberg, H (1986). GC-MS methods for lower plant glycolipid fatty acids. Gas Chromatography/Mass Spectrometry (Linskens, H F and Jackson, J F eds.). Modern Methods of Plant Analysis (New Series). Vol. 3. Springer, Berlin, Heidelberg. p. 67-99.

Park, J; Gu, Y; Lee, Y; Yang, Z and Lee, Y (2004). Phosphatidic acid induces leaf cell death in Arabidopsis by activating the Rho-related small G protein GTPase- mediated pathway of reactive oxygen species generation. Plant Physiol., 134: 129136.

Rees, R W; Flood, J; Hasan, Y; Potter, U and Cooper, R M (2009). Basal stem rot of oil palm (Elaeis guineensis); mode of root infection and lower stem invasion by Ganoderma boninense. Plant Pathol., 58: 982-989.

Rojas, C M; Senthil-Kumar, M; Tzin, V and Mysore, K S (2014). Regulation of primary plant metabolism during plant-pathogen interactions and its contribution to plant defense. Front. Plant Sci., 5(17): $1-11$.

Siebers, M; Brands, M; Wewer, V; Duan, Y; Georg, $\mathrm{H}$ and Peter, P (2016). Lipids in plant-microbe interactions. Biochim. Biophys. Acta Mol. Cell Biol. Lipids, 1861(9): 1379-1395.

Spassieva, S D; Markham, J E and Hille, J (2002). The plant disease resistance gene Asc-1 prevents disruption of sphingolipid metabolism during AALtoxin induced programmed cell death. Plant J., 32: 561-572.

Spiegel, S and Milstien, S (2002). Sphingosine 1-phosphate, a key cell signaling molecule. J. Biol. Chem., 277: 25851-25854.

Stobiecki, M; Wojtaszek, P and Gulewicz, K (1997). Application of solid phase extraction for profiling quinolizidine alkaloids and phenolic compounds in Lupinus albus. Phytochem. Anal., 8(4): 153-158.

Su, T; Zhou, B; Cao, D; Pan, Y; Hu, M; Zhang, M; Wei, H and Han, M (2021). Transcriptomic profiling of Populus roots challenged with Fusarium reveals differential responsive patterns of invertase and invertase inhibitor-like families within carbohydrate metabolism. J. Fungi, 7(2): 89.
Tanaka, T; Abbas, H K and Duke, S O (1993). Structure-dependent phytotoxicity of fumonisins and related compounds in duckweed bioassay. Phytochemistry, 33: 779-785.

Tay, Z H and Chong, K P (2016). The potential of papaya leaf extract in controlling Ganoderma boninense. IOP Conf. Series: Earth and Env. Sci., 36(1): 012027.

Teichmann, B; Lefebvre, F; Labbé, C; Bölker, M; Linne, U and Bélange, R R (2011). Beta hydroxylation of glycolipids from Ustilago maydis and Pseudozyma flocculosa by an NADPH-dependent $\beta$-hydroxylase. Appl. Environ. Microbiol., 77: 7823-7829.

Toh Choon, R L; Sariah, M and Siti Mariam, M N (2012). Ergosterol from the soilborne fungus Ganoderma boninense. J. Basic Microbiol., 52: 608-612.

Wang, H; Li, J; Bostock, R M and Gilchrist, D $G$ (1996). Apoptosis: A functional paradigm for programmed plant cell death induced by a host selective phytotoxin and invoked during development. Plant Cell, 8: 375-391.

Wang, X; Li, J and Zhu, P (2017). Effect of Sclerotinia sclerotiorum on lipid metabolism in Arabidopsis thaliana. J. Plant Dis. Prot., 124(5): 421-426.

Wright, B S; Snow, J W; O’Brien, T C and Lynch, D V (2003). Synthesis of 4-hydroxysphinganine and characterization of sphinganine hydroxylase activity in corn. Arch. Biochem. Biophys., 415: 184192.

Xie, L-J; Chen, Q-F; Chen, M-X; Yu, L-J; Huang, L; Chen, L; Wang, F-Z; Xia, F-N; Zhu, T-R; Wu, J-X; Yin, J; Liao, B; Shi, J; Zhang, J-H; Aharoni, A; Yao, N; Shu, W and Xiao, S (2015). Unsaturation of very-long-chain ceramides protects plant from hypoxia-induced damages by modulating ethylene signaling in Arabidopsis. PLoS Genetic, 11(3): e1005143.

Zianni, R; Bianco, G; Lelario, F; Losito, I; Palmisano, F and Cataldi, T R (2013). Fatty acid neutral losses observed in tandem mass spectrometry with collision-induced dissociation allows regiochemical assignment of sulfoquinovosyl-diacylglycerols. J. Mass Spectrom., 48(2): 205-215. 